\title{
The synergistic effect of calcium on organic carbon sequestration to ferrihydrite
}

\author{
Tyler D. Sowers ${ }^{1 *}$, Jason W. Stuckey ${ }^{1,2}$ and Donald L. Sparks ${ }^{1}$
}

\begin{abstract}
Sequestration of organic carbon (OC) in environmental systems is critical to mitigating climate change. Organomineral associations, especially those with iron (Fe) oxides, drive the chemistry of OC sequestration and stability in soils. Short-range-ordered Fe oxides, such as ferrihydrite, demonstrate a high affinity for $\mathrm{OC}$ in binary systems. Calcium commonly co-associates with $\mathrm{OC}$ and Fe oxides in soils, though the bonding mechanism (e.g., cation bridging) and implications of the co-association for OC sequestration remain unresolved. We explored the effect of calcium $\left(\mathrm{Ca}^{2+}\right)$ on the sorption of dissolved OC to 2-line ferrihydrite. Sorption experiments were conducted between leaf litter-extractable $\mathrm{OC}$ and ferrihydrite at $\mathrm{pH} 4$ to 9 with different initial $\mathrm{C} / \mathrm{Fe}$ molar ratios and $\mathrm{Ca}^{2+}$ concentrations. The extent of $\mathrm{OC}$ sorption to ferrihydrite in the presence of $\mathrm{Ca}^{2+}$ increased across all tested $\mathrm{pH}$ values, especially at $\mathrm{pH}$

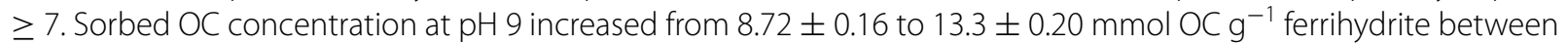
treatments of no added $\mathrm{Ca}^{2+}$ and $30 \mathrm{mM} \mathrm{Ca}{ }^{2+}$ addition. Batch experiments were paired with spectroscopic studies to probe the speciation of sorbed OC and elucidate the sorption mechanism. ATR-FTIR spectroscopy analysis revealed that carboxylic functional moieties were the primary sorbed $\mathrm{OC}$ species that were preferentially bound to ferrihydrite and suggested an increase in Fe-carboxylate ligand exchange in the presence of $\mathrm{Ca}$ at $\mathrm{pH}$ 9. Results from batch to spectroscopic experiments provide significant evidence for the enhancement of dissolved OC sequestration to 2-line ferrihydrite and suggest the formation of Fe-Ca-OC ternary complexes. Findings of this research will inform modeling of environmental $\mathrm{C}$ cycling and have the potential to influence strategies for managing land to minimize OM stabilization.
\end{abstract}

Keywords: Organic carbon, Iron oxide, Climate change, Ternary complexes, Soil

\section{Background}

On a global scale, soil organic matter $(\mathrm{OM})$ sequesters more carbon $(\mathrm{C})$ than vegetation and the atmosphere combined [1, 2]. Soil OM acts a reservoir for organic carbon (OC), making OM a vital component to ensuring soil health and productivity [1-4]. Instability of $\mathrm{OM}$ may lead to increased atmospheric $C$ inputs, a primary mechanism of climate change $[1,2,5,6]$. Historically, the stability of OM in soils and sediments was thought to be controlled largely by the chemistry of the OM present $[2$, 7]. However, this focal point of soil $\mathrm{C}$ cycling research has shifted over the past 15 years [8-10]. Recent research

\footnotetext{
*Correspondence: tdsowers@udel.edu

${ }^{1}$ Department of Plant and Soil Sciences and Delaware Environmental Institute, University of Delaware, 221 Academy Street, ISE Lab, Newark, DE 19711, USA

Full list of author information is available at the end of the article
}

investigating soil $\mathrm{C}$ cycling has concentrated on how environmental processes such as organo-mineral interactions, soil physical properties, and microorganisms control the cycling of $C$ in the environment $[2,11-13]$. Metal oxides, found ubiquitously in soils, have been examined extensively due to a high reactivity and sorption affinity for soil OC [10, 13-16], displaying a high potential to drive the chemistry governing soil $C$ cycling.

Metal oxides immobilize OC in soils by forming protective sorption complexes with OM [13, 15, 17-21]. Iron, $\mathrm{Mn}$, and $\mathrm{Al}$ oxide minerals are primary $\mathrm{OM}$-stabilizing soil constituents $[13,16,18,20]$; however, Fe(III) oxide minerals are of particular environmental importance. Compared to $\mathrm{Mn}$ and $\mathrm{Al}$ oxides, $\mathrm{Fe}(\mathrm{III})$ oxides may sequester $\mathrm{OC}$ to a higher extent and may provide increased stability of sorbed OC [18, 22-26]. Although phyllosilicates also sequester OC, the degree of sorption 
is lower than that of $\mathrm{Fe}(\mathrm{III})$ oxide minerals by approximately an order of magnitude [27]. Poorly-ordered Fe(III) mineral phases, such as 2-line ferrihydrite, are of primary importance as these phases have the highest surface area and reactivity compared to more crystalline phases [9, $15,23,28,29]$. Also, sorption of dissolved OC to 2-line ferrihydrite has been found to be resistant to desorption under similar conditions to the initial OC sorption $[15,17]$. The binding mechanism facilitating OC sorption to Fe(III) oxides has long been investigated using a variety of spectroscopic methods including attenuated total reflectance-Fourier transform infrared spectroscopy (ATR-FTIR), diffuse reflectance infrared Fourier transform spectroscopy (DRIFT), X-ray photoelectron spectroscopy (XPS), and X-ray absorption spectroscopy (XAS) [30]. Many of these studies suggest the sorption of $\mathrm{OM}$ to $\mathrm{Fe}(\mathrm{III})$ metal oxides occurs through a ligand exchange mechanism with the potential for additional outer-sphere complexation varying based on solution $\mathrm{pH}$ and ionic strength $[15,20,31]$. Ligand exchange occurs primarily through exchange of OC carboxyl functional moieties with hydroxyl groups [8, 13-15, 20, 32]. Aromatic groups are associated with Fe, though potentially through carboxyl attachment to aromatic rings [14]. However, the mechanism of OC sorption to metal oxides is still an area of intense research due to wide-ranging results concerning the reactivity of soil sorbents arising from the complexity of OM and technical difficulty in analyzing mechanisms dictating $\mathrm{OC}$ sequestration. Therefore, there is a need for further exploration of the organo-mineral associations controlling environmental $\mathrm{C}$ cycling. An important step forward in improving the current soil $\mathrm{C}$ cycling knowledge base is to investigate the cycling of $\mathrm{OC}$ in chemically complex ternary systems.

Much of the current understanding of OM sequestration in environmental systems has focused solely on binary systems of OC and Fe [13, 14]; however, the prevalence of divalent cations such as calcium $(\mathrm{Ca})$ and magnesium $(\mathrm{Mg})$ may affect the environmental cycling of $\mathrm{C}$ via ternary complex formation. The formation of bridging complexes between metal oxides and $\mathrm{OM}$ has been briefly discussed in the literature [20] but significant evidence of the occurrence and sorption behavior of these complexes in environmental systems is scare. Recent research on ternary complex formation in systems containing iron oxides have been found to play a role in arsenate and phosphate sequestration. Antelo et al. [33] found increasing $\mathrm{Ca}$ concentration in ferrihydrite and arsenate/phosphate systems resulted in increased arsenate/phosphate sequestration at $\mathrm{pH} \geq 8$ along with a corresponding decrease in aqueous $\mathrm{Ca}$ concentration. The results observed in this study provide a promising analogue to research probing the sequestration of $\mathrm{OC}$ as $\mathrm{Fe}-\mathrm{Ca}-\mathrm{OM}$ ternary complexes. Weng et al. [10], for example, suggests that $\mathrm{OC}$ sorption to metal oxides may exhibit behavior similar to polyvalent ions such as phosphate, which implies that potential ternary complexation behavior for ferrihydrite, $\mathrm{Ca}$, and $\mathrm{OC}$ may occur similarly to reported ferrihydrite, $\mathrm{Ca}$, and phosphate ternary complexes [33]. Preliminary evidence exists for the presence of $\mathrm{Ca}$ associations with $\mathrm{Fe}$ and $\mathrm{OC}$ in environmental systems. The use of synchrotron-based scanning transmission X-ray microscopy (STXM) has shown significant correlation between $\mathrm{Ca}$ and $\mathrm{C}$ in the clay fraction of soils that contain high $\mathrm{Fe}$ content but do not have carbonate minerals [8]. Humic acid sorption to Fe(III) minerals is promoted by the presence of $\mathrm{Ca}[34,35]$. These results in conjunction with the known association of Fe and $\mathrm{OM}$ suggest that $\mathrm{Ca}$ may be an important factor determining OC sequestration and deserve further investigation.

Research probing the mechanism and sequestration extent of OC sequestration to Fe oxide is needed to reliably model $\mathrm{C}$ cycling in environmental systems. Examining the effect of polyvalent ions such as $\mathrm{Ca}$ on $\mathrm{OC}$ sequestration could have major impacts on how $\mathrm{C}$ cycling is modeled in natural systems. To explore the effect of $\mathrm{Ca}$ on $\mathrm{OC}$ sorption to Fe oxides, we 1) determined the impact of $\mathrm{Ca}$ on dissolved organic carbon (DOC) sorption on 2-line ferrihydrite and 2) probed the mechanism of expected $\mathrm{Fe}-$ $\mathrm{Ca}-\mathrm{OC}$ ternary complexes. We expected that $\mathrm{Ca}$ enhanced the sorption extent of $\mathrm{OC}$ through the formation of bridging structures between Fe and OC. The following research strives to provide chemical evidence for the potential formation of $\mathrm{Fe}-\mathrm{Ca}-\mathrm{OC}$ ternary complexation.

\section{Natural and laboratory sources of organic carbon}

Both natural and model (citric acid) organic carbon sources were tested to determine the effect of $\mathrm{Ca}$ on $\mathrm{OC}$ sorption to synthetic 2-line ferrihydrite. Water-extractable dissolved organic matter (DOM) was used as a natural source of OC. Leaf litter used for the DOM extraction was obtained from the Stroud Water Research Center (Avondale, PA). Samples were collected from the top $10 \mathrm{~cm}$ of leaf litter from a forest soil $\mathrm{O}_{\mathrm{a}}$ horizon (Typic Hapludult). Using a method adapted from Chen et al. and Stuckey et al. [14, 26], soil-organic materials were mixed with DI water for $90 \mathrm{~h}$ (1:2 fresh leaf litter:DI water [w/w]) while being vigorously stirred $(200 \mathrm{rpm})$ on a rotary shaker. After a 90-h equilibration time, the resulting solution was centrifuged $(20,000 \mathrm{~g}$ for $1 \mathrm{~h})$ and sequentially vacuum filtered through polyethersulfone filters of $0.8,0.45$, and $0.2 \mu \mathrm{m}$ pore size. Sequential filtration was performed due to the large range in particle size of the leaf litter extract. The filtered DI-extractable DOM solution was then analyzed using a total organic carbon (TOC) analyzer (Apollo 9000 series) to determine OC concentration 
(Additional file 1: Table S1). A metal/metalloid elemental analysis of the DOM solution was performed using inductively coupled plasma-atomic emission (ICP-AES) (Additional file 1: Table S2). Citric acid was chosen as a model OC compound analogue for our study. Citric acid (Sigma Aldrich) is a tricarboxylic acid and was chosen due to the high reactivity of the carboxylic acid moiety, high concentration of carboxylic acid from DOM extracted from the same leaf litter site [14], and the favorable sorption of carboxylic acid to iron oxides [13, 15]. Attenuated total reflectance-Fourier transform infrared spectroscopy (ATR-FTIR) analysis of the DOM (Table 2) confirmed that carboxylic acid is the dominant $\mathrm{C}$ moiety present (assignment), with aromatic $\left(1585 \mathrm{~cm}^{-1}\right)$, phenolic $\left(1270 \mathrm{~cm}^{-1}\right)$, and polysaccharide $\left(1120,1080\right.$, and $\left.1040 \mathrm{~cm}^{-1}\right)$ groups present to a lesser degree.

\section{Synthetic 2-line ferrihydrite synthesis}

Two-line ferrihydrite, a ubiquitously found $\mathrm{Fe}(\mathrm{III})$ oxide, was synthesized according to procedures established in Cornell and Schwertmann [23]. $40 \mathrm{~g}$ of $\mathrm{Fe}\left(\mathrm{NO}_{3}\right)_{3} \cdot 9 \mathrm{H}_{2} \mathrm{O}$ was dissolved in $500 \mathrm{~mL}$ of deionized (DI) water. In order to bring the $\mathrm{pH}$ to a range of 7-8, $330 \mathrm{~mL}$ of $1 \mathrm{M} \mathrm{KOH}$ was added, while stirring, to a $\mathrm{Fe}\left(\mathrm{NO}_{3}\right)_{3} \cdot 9 \mathrm{H}_{2} \mathrm{O}$ solution. The $\mathrm{pH}$ of the solution was continuously monitored during the addition of the final $20 \mathrm{~mL}$ of $1 \mathrm{M} \mathrm{KOH}$. Upon reaching this $\mathrm{pH}$ range, the solution was centrifuged and dialyzed, yielding $10 \mathrm{~g}$ of 2 -line ferrihydrite.

\section{Sorption isotherms}

Multiple adsorption isotherm experiments were performed to test the effect of increasing DOC concentration and/or the effect of increasing Ca concentration on OC sorption to synthetic 2-line ferrihydrite. The previously discussed DOM stock was used as a source of OC for all adsorption experiments. Prior to beginning sorption experiments, the DOM stock was determined to have an OC concentration of approximately $2000 \mathrm{mg}$ $\mathrm{OC} \mathrm{L}^{-1}$ and a Ca concentration of approximately $4 \mathrm{mM}$ $\mathrm{Ca}$. Each reactor received $43 \mathrm{mg}$ of 2-line ferrihydrite as a wet paste and was suspended with $40 \mathrm{~mL}$ of DOM stock diluted with Type 1 deionized (DI) water to achieve a series of initial OC concentrations, such that the $\mathrm{C} / \mathrm{Fe}$ molar ratio ranged from 0.3-16.9. Initial Ca concentration increased as initial DOM concentration increased due to the inherent $\mathrm{Ca}$ concentration present in the DOM stock, resulting in $\mathrm{Ca}$ concentration increasing up to $4 \mathrm{mM} \mathrm{Ca}$ for the most concentrated DOM sample (initial C/Fe molar ratio of 16.9). The $\mathrm{pH}$ of the suspensions was adjusted to $6.25 \pm 0.10$ using $\mathrm{NaOH}$ and/or $\mathrm{HCl}$ in order to perform experiments at an environmentally relevant $\mathrm{pH}$. All samples were covered and mixed via a rotary shaker $(50 \mathrm{rpm})$ in the dark for $24 \mathrm{~h}$ after $\mathrm{pH}$ adjustment. The 24-h equilibration time was determined by performing preliminary sorption experiments, in which maximum OC sorption was reached within $24 \mathrm{~h}$. Sample pH was monitored intermittently throughout the equilibration time to ensure that the $\mathrm{pH}$ remained at $6.25 \pm 0.10$. Upon completion of the 24-h equilibration, samples were centrifuged $(20,000 \mathrm{~g})$ and the supernatant was collected for TOC and ICP-AES analysis. Solid samples were washed at least twice with DI water and stored moist in a freezer at approximately $-4{ }^{\circ} \mathrm{C}$ until further analysis. Analogous control experiments were performed with citric acid as the $C$ source rather than natural DOM. All sorption isotherm experiments here and throughout were performed in at least duplicate.

For the next series of sorption isotherm experiments, the previously detailed procedure was repeated, expect $\mathrm{CaCl}_{2}$ was added to each reactor such that the final $\mathrm{Ca}$ concentration was equal to the $\mathrm{Ca}$ concentration of the sample receiving the greatest concentration of DOM solution $(\sim 4 \mathrm{mM} \mathrm{Ca})$. For citric acid experiments, which contain no native $\mathrm{Ca}$ concentration, $\mathrm{CaCl}_{2}$ was added to match the $\mathrm{Ca}$ concentration of the DOM experiments. Lastly, separate sorption isotherms testing the effect of increasing $\mathrm{Ca}$ concentrations were performed for $\mathrm{C} / \mathrm{Fe}$ molar ratios of 4.7 and 12.5. Calcium chloride was added to each sample such that the initial $\mathrm{Ca}$ concentration ranged from approximately $1 \mathrm{mM} \mathrm{Ca}$ to $60 \mathrm{mM} \mathrm{Ca}$. All other steps were carried out as described for the $4 \mathrm{mM}$ $\mathrm{Ca}$ sorption experiments. Prior to performing experiments with increasing Ca concentration, a subsample of stock DOM solution was equilibrated with $100 \mathrm{mM} \mathrm{Ca}$ (via $\mathrm{CaCl}_{2}$ ) to ensure no precipitates formed. No precipitates were formed after shaking for a 24-h equilibration time.

TOC analysis was performed before and after sorption of DOM to 2-line ferrihydrite for all experiments. The quantity of $\mathrm{OC}$ sorbed was calculated by measuring the difference between the $\mathrm{OC}$ concentrations before and after sorption. Sorption isotherm data were processed and fit to the Langmuir equation using a preprogrammed Excel sheet [36].

\section{Sorption envelopes}

The effect of $\mathrm{pH}$ and $\mathrm{Ca}$ concentration at an initial $\mathrm{C} / \mathrm{Fe}$ molar ratio of 4.7 was determined by conducting sorption envelope experiments with DOM and 2-line ferrihydrite. The experimental setup was equivalent to what was performed for sorption isotherm reactions discussed previously; however, initial $\mathrm{OC}$ concentration was consistent across all samples and $\mathrm{pH}$ was the variable being changed. All samples contained $43 \mathrm{mg}$ of 2-line ferrihydrite and were suspended in the DOM stock solution such that the initial C/Fe molar ratio equaled 4.7. Subsequently, sample 
$\mathrm{pH}$ was adjusted with $\mathrm{HCl}$ and $\mathrm{NaOH}$ (accounted for $<1 \%$ of total solution volume) from $\mathrm{pH} 4$ to 9 . All envelope experiments were then shaken in the dark for $24 \mathrm{~h}$ and then sampled according to the sorption isotherm procedure discussed earlier. Separate envelope experiments were performed at different $\mathrm{Ca}$ concentrations (via $\mathrm{CaCl}_{2}$ addition), which consisted of approximately 1 (background DOM concentration), 10 , or $30 \mathrm{mM} \mathrm{Ca}$ in order to capture typical behavior at high soil porewater Ca concentrations [33, 37]. Control sorption envelope experiments were performed with only $\mathrm{Ca}$ and 2-line ferrihydrite to evaluate $\mathrm{Ca}$ sorption to ferrihydrite without DOM. Aqueous and solid samples from the sorption envelope experiments were collected after $24 \mathrm{~h}$ of reaction time and analyzed similarly to what was described earlier for sorption isotherm experiments. Before beginning envelope experiments, subsamples of DOM stock were adjusted from $\mathrm{pH} 4$ to 9 to determine if any precipitates formed. No precipitates were observed after $24 \mathrm{~h}$.

\section{ATR-FTIR spectroscopy}

Freeze-dried DOM and ferrihydrite samples were analyzed using a Bruker ATR-FTIR. Spectra were scanned from 4000 to $600 \mathrm{~cm}^{-1}$ at a spectra resolution of $2 \mathrm{~cm}^{-1}$. 2-line ferrihydrite spectra was subtracted from all OCbearing ferrihydrite samples to remove contributions from ferrihydrite to focus on the chemical composition of the bound OC. Automatic baseline correction and normalization was applied to all spectra. All samples were dried and analyzed soon after to avoid the effects of moisture uptake on sample spectra. The OPUS Version 7.2 spectroscopy software suite (Bruker) was used to process all collected spectra.

\section{Additional characterization techniques}

X-ray diffraction (XRD) and Brunauer-Emmett-Teller (BET) analysis were performed to confirm the mineralogy and external surface area of synthesized 2-line ferrihydrite, respectively. A Bruker D8 Discover diffractometer was used to perform XRD analysis. A synthesized iron oxide sample was freeze-dried prior to analysis and analyzed from $20^{\circ}$ to $75^{\circ} 2 \theta$ (step size $0.05^{\circ} 2 \theta$ ). The analysis confirmed the synthesis of 2-line ferrihydrite (Additional file 1: Figure S1). The BET surface area of synthesized 2-line ferrihydrite was found to be $288.57 \mathrm{~m}^{2} \mathrm{~g}^{-1}$, which is within the BET surface area range reported for synthetic ferrihydrite [23]. A vario Micro cube CHNS analyzer was used for a subset of OC-bearing ferrihydrite samples to confirm that the quantity of sorbed $C$ in the solid phase was consistent with that removed from the liquid phase before and after reaction (data not shown).

A subset of sorption samples was digested to supplement aqueous Fe and $\mathrm{Ca}$ data. A $10 \mathrm{mg}$ sample of 2-line ferrihydrite was digested using aqua regia (3:1 molar ratio of $\mathrm{HCl}$ and $\mathrm{HNO}_{3}$ ) and measured for $\mathrm{Fe}$ and $\mathrm{Ca}$ using ICP-AES.

\section{Results and discussion \\ Effect of Ca on the sorption extent of DOM and citric acid to ferrihydrite}

All isotherm data was well described by the Langmuir equation with $\mathrm{OC}$ sorbed concentrations increasing rapidly at low solution OC concentrations, with decreasing slope at high equilibrium concentrations (Fig. 1, Table 1). This sorption phenomenon is consistent with the L-type isotherm; therefore, the Langmuir equation was chosen over the Freundlich to fit all sorption isotherm data as the Langmuir equation was found to have a superior goodness of fit $[5,38]$. All Langmuir fitting parameters $\left(S=\left(S_{\max } K C\right) /(1+K C)\right.$ where $\mathrm{S}$ is the sorbed concentration, $\mathrm{S}_{\max }$ is the predicted maximum sorbed concentration, $K$ is a sorption constant, and $C$ is the equilibrium sorbate concentration) are shown in Table 1.

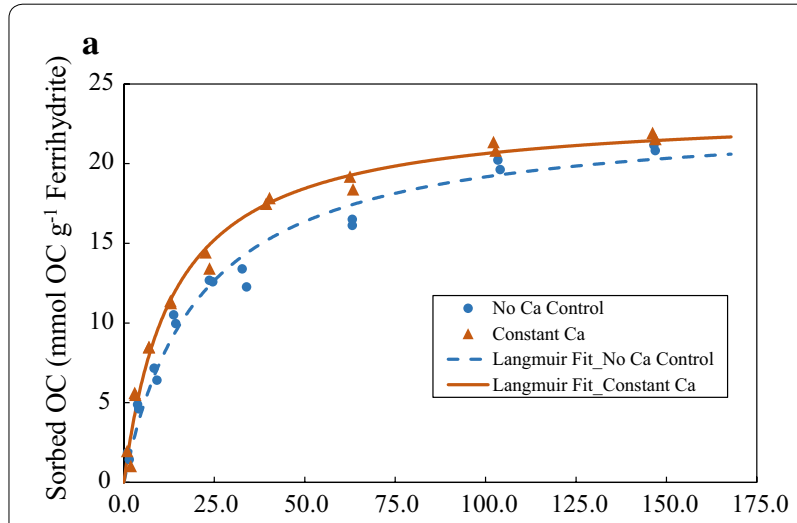

Equilibrium Organic Carbon Concentration (mmol OC L-1)

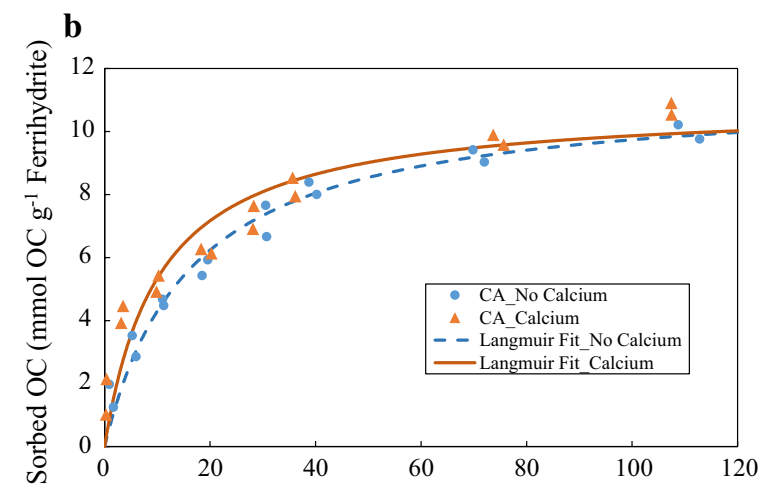

Equilibrium Organic Carbon Concentration ( $\mathrm{mmol} \mathrm{OC} \mathrm{L}^{-1}$ )

Fig. 1 Sorption behavior of organic carbon to 2-line ferrihydrite: DOM (a) and citric acid (b) were reacted with ferrihydrite at $\mathrm{pH}$ $6.25 \pm 0.10$ in duplicate. Samples were treated with and without $\mathrm{Ca}$ addition. Sample receiving Ca had a total Ca concentration of $4 \mathrm{mM}$ Ca (152 $\left.\mathrm{mg} \mathrm{Ca} \mathrm{L}^{-1}\right)$ 
Table 1 Langmuir parameters used to model sorption of DOM and citric acid to 2-line ferrihydrite

\begin{tabular}{lllll}
\hline Organic C source & Calcium treatment & $\mathbf{S}_{\max }\left(\mathbf{m m o l} \mathbf{O C} \mathbf{~ g}^{\mathbf{- 1}}\right.$ ferrihydrite $)$ & K & $\mathbf{E}$ \\
\hline DOM & No Ca control & $23.13 \pm 0.7455$ & $0.004 \pm 0.001$ & 0.978 \\
& 4 mM Ca & $23.41 \pm 0.5125$ & $0.006 \pm 0.001$ & 0.989 \\
Citric acid & No calcium & $11.32 \pm 0.4690$ & $0.005 \pm 0.001$ & 0.967 \\
& 4 mM Ca & $10.89 \pm 0.6903$ & $0.008 \pm 0.002$ & 0.906 \\
\hline
\end{tabular}

$S_{\max }$ predicted maximum sorbed concentration; $K$ sorption constant; $E$ model efficiency

In Fig. 1a, DOM sorption to 2-line ferrihydrite data was fit using the Langmuir equation with a high model efficiency for the data sets with and without Ca control ( 0.978 and 0.989 , respectively). The Langmuir parameters for the non-Ca controlled and $\mathrm{Ca}$ controlled data sets were similar. Two differing sets of isotherms, one where DOM was reacted with 2-line ferrihydrite without the addition of $\mathrm{CaCl}_{2}$ and the other where $\mathrm{CaCl}_{2}$ was added such that $\mathrm{Ca}$ concentration was constant across all initial $\mathrm{C} / \mathrm{Fe}$ concentrations, were performed to determine the effect of Ca control on DOM sorption on 2-line ferrihydrite. The maximum sorbed OC concentration for both data sets was observed to be $23.13 \mathrm{mM}$ OC for the most concentrated DOM sample (initial $\mathrm{C} / \mathrm{Fe}$ molar ratio of 16.9). The observed sorption maximum is mostly consistent with what Chen et al. observed at $\mathrm{pH} 7$, although our experiments resulted in approximately $10 \%$ higher sorption relative to a system without exogenous calcium [14]. Although the Langmuir fitting parameters for the data sets were similar, the sorbed OC concentration from 25 to $75 \mathrm{mM}$ equilibrium $\mathrm{OC}$ for the $\mathrm{Ca}$ controlled isotherm was found to differ by approximately $10 \%$ to $15 \%$. The difference in sorption at the 25 to $75 \mathrm{mM}$ equilibrium $\mathrm{OC}$ concentration range was attributed to differences in $\mathrm{Ca}$ concentration ( $1 \mathrm{mM}$ Ca for non-Ca controlled isotherm samples versus $\sim 4 \mathrm{mM} \mathrm{Ca}$ for $\mathrm{Ca}$-controlled isotherm samples) (Fig. 1).

Analogous sorption isotherm experiments, with and without fixed $\mathrm{Ca}$ concentration, were conducted using citric acid as an OC source. The sorption extent of citric acid to 2-line ferrihydrite was significantly less than that of DOM $\left(\mathrm{S}_{\max }=11.32\right)$. The decreased affinity of citric acid to iron oxides compared to natural DOM is supported by the literature, although the observed sorption maximum for citric acid experiments was approximately an order of magnitude greater than that of citric acid sorption to goethite experiments [39]. The lesser reactivity and surface area of goethite compared to 2-line ferrihydrite is the most likely reason for the observed disparity in sorption maximum. Unlike what was observed for DOM experiments, no significant differences in sorption extent were observed between data sets of no $\mathrm{Ca}$ addition and $4 \mathrm{mM} \mathrm{Ca}$ addition. These results suggest that $\mathrm{Ca}$ does not have an effect on the sorption of $\mathrm{OC}$ as citric acid to 2-line ferrihydrite. The DOM source has been found to consist of predominately carboxylic functional moieties through ATR-FTIR (Fig. 5) and past studies [14]; therefore, it is surprising that citric acid sorption behavior differs from DOM. Chemical heterogeneity of natural DOM compared to a simple model compound such as citric acid is a probable reason for the observed difference and suggests that citric acid may not be a representative analogue when modeling $\mathrm{OC}$ cycling in natural systems.

\section{Effect of $\mathrm{pH}$ and Ca concentration on DOM sorption}

Sorption envelope experiments were performed to determine the concentration of sorbed OC, as DOM, to 2-line ferrihydrite from $\mathrm{pH}$ 4-9 at differing initial Ca concentrations (Fig. 2). An initial C/Fe molar ratio of 4.7 was used for all sorption envelope experiments and zero Ca (native concentration of $\sim 1 \mathrm{mM}$ Ca from DOM), $10 \mathrm{mM} \mathrm{Ca}$, or $30 \mathrm{mM} \mathrm{Ca}$ were added. The sorption

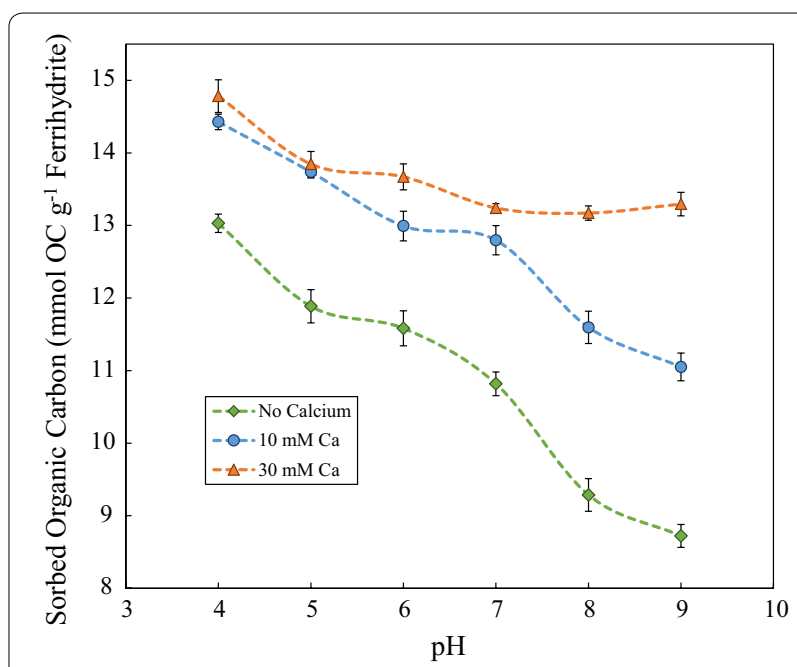

Fig. 2 The effect of $\mathrm{pH}$ on DOM sorption to 2-line ferrihydrite: sorption envelopes of DOM sorption to ferrihydrite at $\mathrm{pH} 4$ to 9 in the presence of no added Ca (a), $10 \mathrm{mM} \mathrm{Ca}(\mathbf{b})$, or $30 \mathrm{mM} \mathrm{Ca}(\mathbf{c})$. An initial C/Fe ratio of 4.7 was used for all samples and experiments were performed in triplicate 
data for the zero added Ca treatment decreased from a

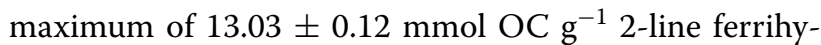
drite as $\mathrm{pH}$ increased, with a major decrease near the 2-line ferrihydrite point of zero charge $(\mathrm{PZC}=\sim 7.5)$. The lowest sorbed $\mathrm{OC}$ concentration was found to be $8.72 \pm 0.16 \mathrm{mmol} \mathrm{OC} \mathrm{g}^{-1} 2$-line ferrihydrite at $\mathrm{pH}$ 9. The decrease in sorbed OC concentration is best explained by the effects of $\mathrm{pH}$ on the variable charge of 2-line ferrihydrite. The 2-line ferrihydrite mineral surface should become less positively charged with increasing $\mathrm{pH}$ until the PZC is reached, after which the mineral surface becomes increasingly negatively charged [5, 23, 26, 38]. However, the addition of $\mathrm{Ca}$ to the system resulted in major differences in sorbed OC concentration, especially at $\mathrm{pH}>\mathrm{PZC}$.

The addition of $\geq 10 \mathrm{mM}$ Ca simultaneously with DOM to the 2-line ferrihydrite system resulted in increased sorbed $\mathrm{OC}$ concentration across all tested pHs. The $10 \mathrm{mM} \mathrm{Ca}$ treatment resulted in approximately $2 \mathrm{mmol} \mathrm{OC} \mathrm{g}{ }^{-1}$ 2-line ferrihydrite more sorption from $\mathrm{pH} 4$ through 7 compared to the data set with no $\mathrm{Ca}$ treatment. The $30 \mathrm{mM} \mathrm{Ca}$ treatment resulted in similar sorbed $\mathrm{OC}$ concentration compared to the $10 \mathrm{mM}$ $\mathrm{Ca}$ treatment from $\mathrm{pH} 4$ through 7, with approximately $0.5 \mathrm{mmol} \mathrm{OC} \mathrm{g}^{-1}$ 2-line ferrihydrite increased sorption at $\mathrm{pH} 6$ and 7. At $\mathrm{pH} \geq 7$ however, all sorbed OC concentration data significantly differed between data sets. Sorbed OC concentration differed greatest between sets at $\mathrm{pH}$ 9, with observed $\mathrm{OC}$ sorbed concentrations of $8.72 \pm 0.16,11.05 \pm 0.19$, and $13.3 \pm 0.20 \mathrm{mmol} \mathrm{OC} \mathrm{g}^{-1}$ 2-line ferrihydrite for the no $\mathrm{Ca}, 10 \mathrm{mM} \mathrm{Ca}$, and $30 \mathrm{mM}$ $\mathrm{Ca}$ treatments, respectively. Another important feature in Fig. 2 is that the $30 \mathrm{mM}$ Ca data set was found to vary only slightly across the $\mathrm{pH}$ 5-9 range. Sorbed $\mathrm{OC}$ concentration of samples at $\mathrm{pH} 4$ and 5 varied by approximately $0.6 \pm 0.2 \mathrm{mmol} \mathrm{OC}^{-1}$ 2-line ferrihydrite, whereas samples at $\mathrm{pH} 7-9$ varied by only approximately $0.15 \pm 0.044 \mathrm{mmol} \mathrm{OC}^{-1}$ 2-line ferrihydrite.

The higher sorption of $\mathrm{OC}$ with $\mathrm{Ca}$ addition and the lower variation in sorbed $\mathrm{OC}$ from $\mathrm{pH}$ 5-9 for the $30 \mathrm{mM}$ Ca data set suggests that Ca enhances sequestration of $\mathrm{OC}$ to 2-line ferrihydrite. Trends similar to those observed in Fig. 2 were observed in systems studying the effect of initial Ca concentration on phosphate/arsenate sorption to 2-line ferrihydrite [33]. Antelo et al. observed high disparity in phosphate sorption concentration at $\mathrm{pH}$ $\geq 7$ with increasing $\mathrm{Ca}$ concentration, the same trend observed in our study for OC sorption concentration. Also, the rate of phosphate sorption decrease declined dramatically with increasing $\mathrm{pH}$ at $6 \mathrm{mM} \mathrm{Ca}$; therefore, the effect of $\mathrm{Ca}$ on phosphate sorption to ferrihydrite appears to be similar to the ferrihydrite-Ca-OC system. The similarity in behavior between phosphate and $\mathrm{OM}$ sorption to Fe oxide has been shown in prior research as well [10], suggesting that ferrihydrite-Ca-phosphate systems may be an appropriate analogue when examining ferrihydrite-Ca-OC systems. The most likely explanation for the observed synergistic effect of $\mathrm{Ca}$ on OC sorption is due to the potential formation of Ca-bridging between ferrihydrite and OC. The high concentration of a divalent cation such as $\mathrm{Ca}^{2+}$ in a system containing negatively charged DOM and ferrihydrite surfaces at $\mathrm{pH} \geq 7$ may facilitate the bridging process and would explain the consistent OC sorption concentration from $\mathrm{pH}$ 5-9 of the $30 \mathrm{mM}$ Ca data set. It was unexpected that OC sorption concentration would be affected by $\mathrm{Ca}$ concentration at $\mathrm{pH} 4$ and 5 due to the system being electrostatically unfavorable for the formation of outer sphere complexes. Ligand exchange processes may be controlling the $\mathrm{Ca}$ effect on OC sorption.

\section{Coupled Ca concentration decrease with increasing pH in batch reactor systems}

Initial $\mathrm{Ca}$ concentrations of $1 \mathrm{mM} \mathrm{Ca}$ (baseline $\mathrm{Ca}$ concentration from DOM), $10 \mathrm{mM} \mathrm{Ca}$, and $30 \mathrm{mM} \mathrm{Ca}$ were tested in 2-line ferrihydrite systems where DOM was added simultaneously with $\mathrm{Ca}$ (Fig. 3). Calcium concentration remained insignificantly changed in the absence of DOM at pH 4-6 for Fig. 3a, b. Above pH 6, aqueous $\mathrm{Ca}$ concentration decreased until aqueous $\mathrm{Ca}$ concentrations of approximately $28.5 \mathrm{mM} \mathrm{Ca}$ and $9.25 \mathrm{mM} \mathrm{Ca}$ (for Fig. 3a, b, respectively) at $\mathrm{pH}$ 9. Antelo et al. also observed no significant change in aqueous $\mathrm{Ca}$ concentration in systems equilibrated with 2-line ferrihydrite at acidic $\mathrm{pH}$ and a decrease in aqueous $\mathrm{Ca}$ concentration as $\mathrm{pH}$ increased [33]. However, Anetelo et al. determined a significant decreases in aqueous $\mathrm{Ca}$ concentration began at approximately $\mathrm{pH} 8.5$, which deviates from our observation of aqueous $\mathrm{Ca}$ concentration decreasing beginning at approximately $\mathrm{pH}$ 7. The disparity is most likely due to differences in experimental setup and potentially differences in mineral charge. The PZC of 2-line ferrihydrite supports our observations as the 2-line ferrihydrite should become negative at $\mathrm{pH}$ higher than approximately 7-7.5. In the presence of DOM, a similar trend was observed for Fig. 3a, b; however, aqueous Ca concentration was lower for a majority of the tested $\mathrm{pH}$ range. In Fig. 3a, aqueous $\mathrm{Ca}$ concentration was similar at $\mathrm{pH}$ 4 for the data sets with and without DOM but the data set with DOM began to decrease to a more significant extent (up to $\sim 0.6 \mathrm{mM}$ Ca difference) than the data set without DOM. A similar trend was observed for Fig. 3b; however, the difference between data sets was within standard error from $\mathrm{pH} 4-6$. Differences in aqueous $\mathrm{Ca}$ concentration between the data sets with and without DOM increased up to $0.45 \mathrm{mM} \mathrm{Ca}$ at $\mathrm{pH}$ 9. Aqueous $\mathrm{Ca}$ 

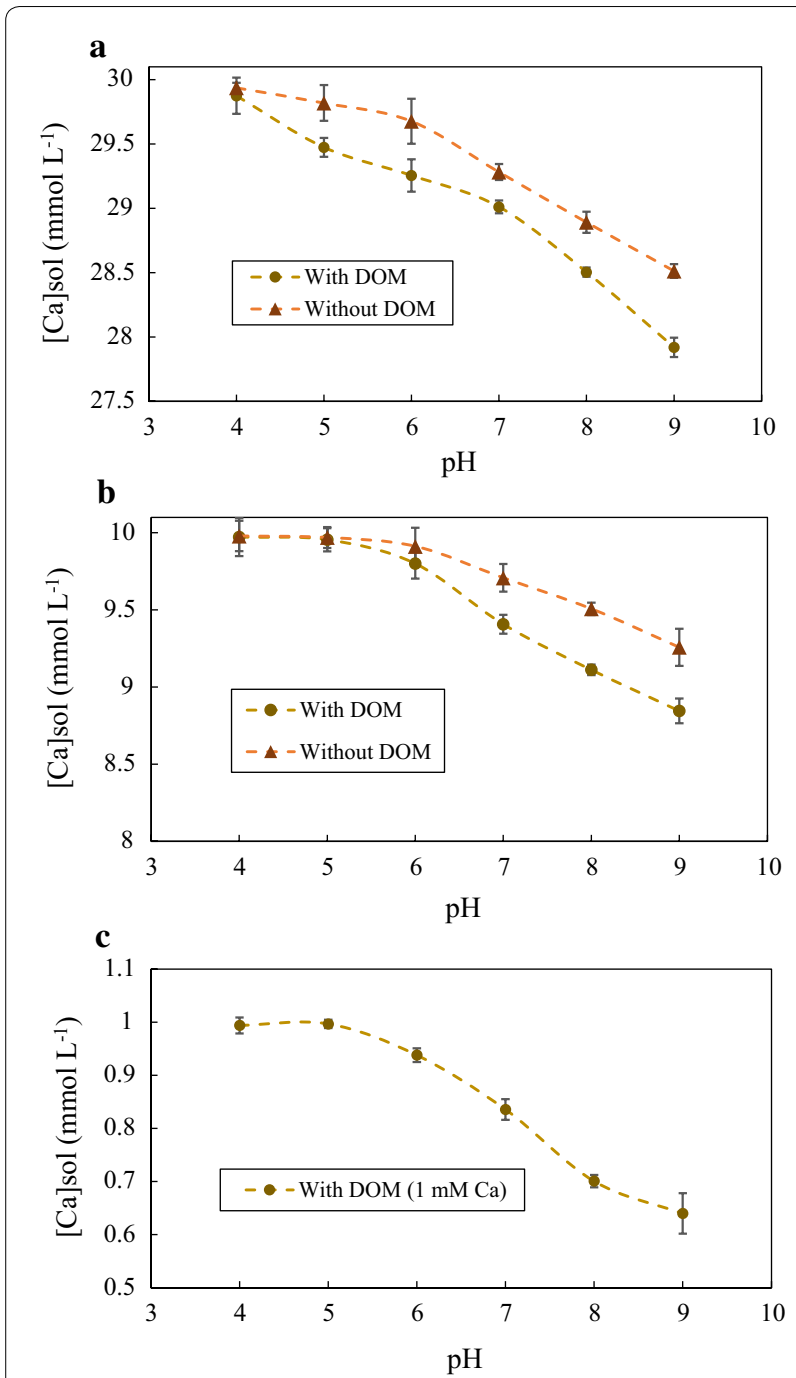

Fig. 3 Calcium sorption behavior on 2-line ferrihydrite: aqueous Ca data from sorption envelope experiments at initial Ca concentrations of 30,10 , and $1 \mathrm{mM} \mathrm{Ca}(\mathbf{a}, \mathbf{b}$, and $\mathbf{c}$, respectively) conducted from $\mathrm{pH}$ 4 to 9 . The multicomponent systems consisted of $\mathrm{Ca}$ and ferrihydrite or $\mathrm{Ca}$, ferrihydrite, and DOM. The greater decrease in aqueous $\mathrm{Ca}$ in the DOM multicomponent system compared to the system without DOM is thought to occur due to ternary interactions of ferrihydrite, $\mathrm{Ca}$, and DOM

concentration data in Fig. 3c was performed at the baseline Ca concentration $(\sim 1 \mathrm{mM} \mathrm{Ca})$ that was present in all sorption experiments (with no added $\mathrm{Ca}$ ) at an initial $\mathrm{C} / \mathrm{Fe}$ molar ratio of 4.7. Aqueous $\mathrm{Ca}$ concentration decreased at the greatest rate from $\mathrm{pH} \mathrm{6-8}$ and at $\mathrm{pH}$ 9, reaching an aqueous $\mathrm{Ca}$ concentration minimum of $0.64 \mathrm{mM} \mathrm{Ca}$.

Aqueous Ca data from Fig. 3 correlate trends observed in Fig. 2. Aqueous $\mathrm{Ca}$ concentration decreased to a greater extent than the Ca-ferrihydrite control for Fig. 3a, $\mathrm{b}$, which coincides with increased sorption of DOM at high $\mathrm{pH}$ and increasing $\mathrm{Ca}$ concentration observed in Fig. 2. Decrease in aqueous $\mathrm{Ca}$ concentration is expected with increasing $\mathrm{pH}$ due to the 2-line ferrihydrite mineral surface becoming increasingly positively charged. However, the observed lower aqueous $\mathrm{Ca}$ concentration in the presence of DOM suggests that $\mathrm{Ca}$ may be interacting with both the DOM and 2-line ferrihydrite.

\section{Increased DOM sequestration with Increasing Ca concentration}

The effect of initial $\mathrm{Ca}$ concentration was further explored by performing separate DOM sorption experiments for initial $\mathrm{C} / \mathrm{Fe}$ molar ratios of 4.7 and 12.5 with increasing $\mathrm{Ca}$ concentration (Fig. 4). Both the 4.7 and $12.5 \mathrm{C} / \mathrm{Fe}$ data sets were observed to have similar trends in sorbed $\mathrm{OC}$ concentration with initial $\mathrm{Ca}$ concentration ranging up to $60 \mathrm{mM} \mathrm{Ca}$. Sorbed $\mathrm{OC}$ concentration increased linearly with increasing $\mathrm{Ca}$ concentration until an initial Ca concentration of $20 \mathrm{mM}$ and then began to plateau at approximately $4.5 \mathrm{mmol} \mathrm{OC} \mathrm{g}{ }^{-1}$ 2-line ferrihydrite greater than samples receiving zero initial $\mathrm{Ca}$. Initial $\mathrm{Ca}$ concentrations greater than $60 \mathrm{mM} \mathrm{Ca}$ are expected to continue to increase sorbed $\mathrm{OC}$ concentration but to a lesser extent than what is observed from 0 to $60 \mathrm{mM} \mathrm{Ca}$. Figure 4 provides further evidence that $\mathrm{Ca}$ is enhancing the sequestration of DOM to 2-line ferrihydrite.

\section{ATR-FTIR spectroscopy}

Distinct differences and similarities were observed for ATR-FTIR spectra of sorption complexes formed at differing initial chemical conditions (Fig. 5). Due to

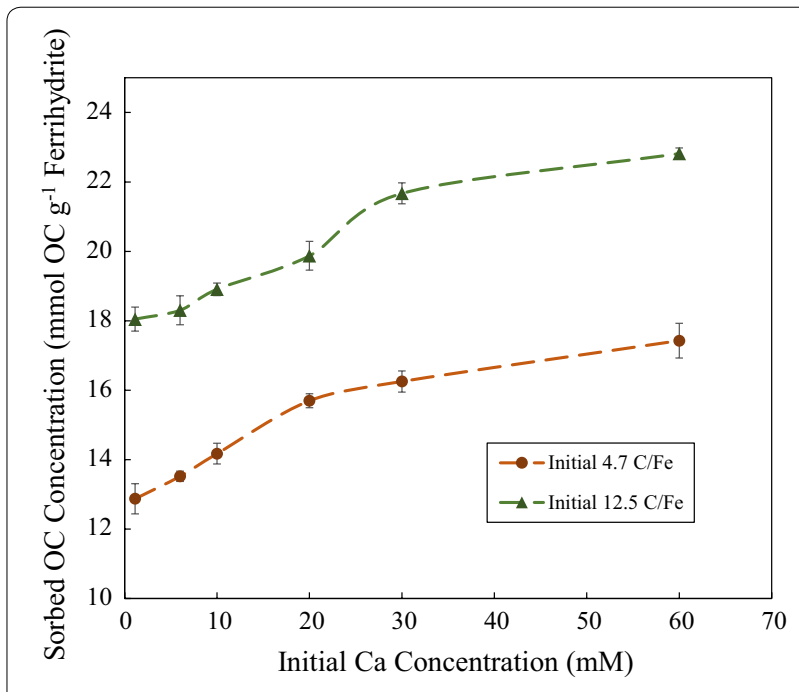

Fig. 4 The effect of calcium concentration on DOM sorption to 2-line ferrihydrite: sorption of DOM to 2-line ferrihydrite at 4.7 and 12.5 initial C/Fe molar ratios with increasing calcium concentration (up to $60 \mathrm{mM} \mathrm{Ca}$ ) at $\mathrm{pH} 6.25 \pm 0.10$ 

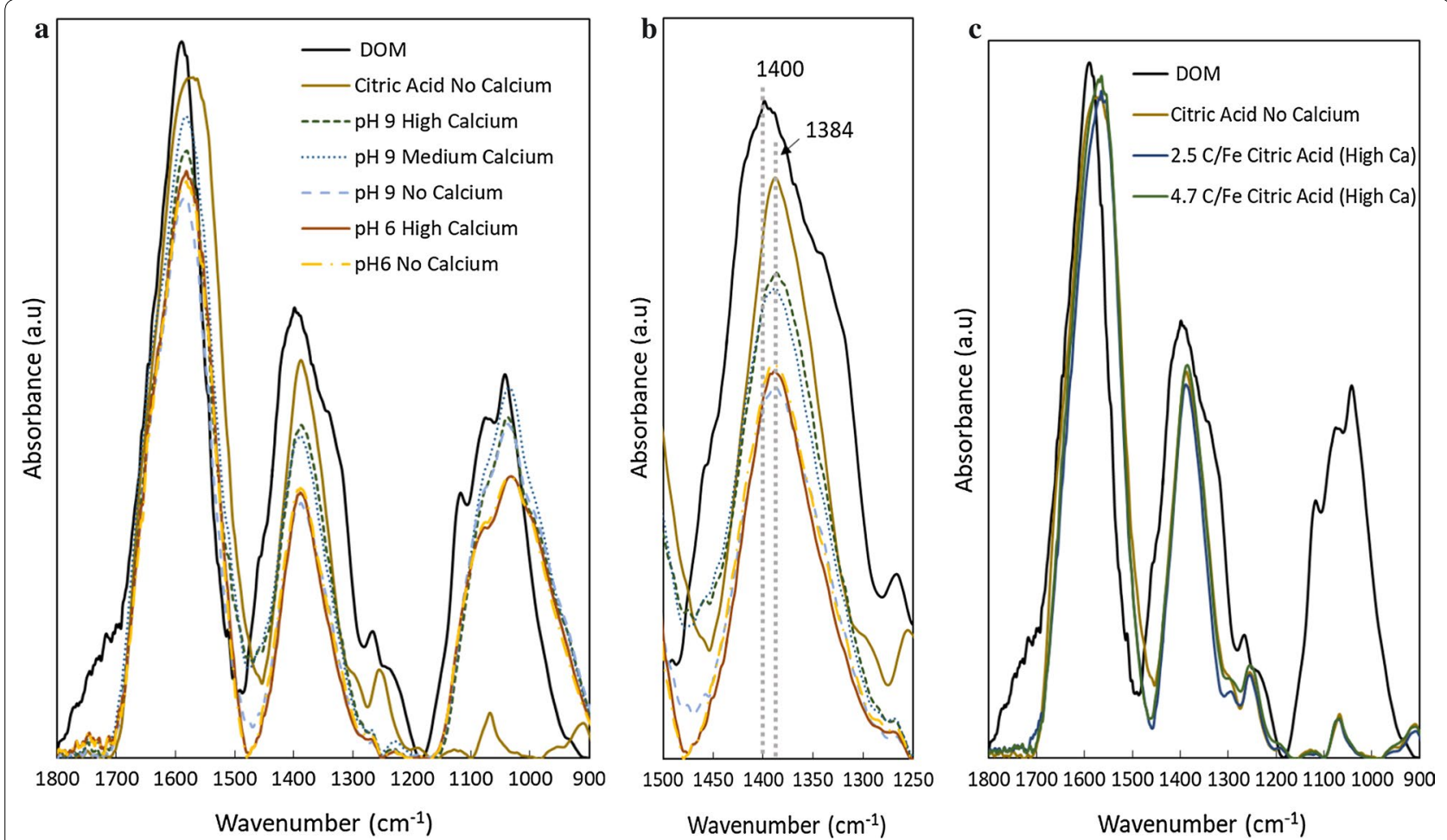

Fig. 5 ATR-FTIR spectra for DOM-bearing 2-line ferrihydrite with and without calcium addition: background corrected and normalized FTIR spectra for DOM (a and $\mathbf{b}$ ) or citric acid-bearing (c) 2-line ferrihydrite in the presence or absence of $\mathrm{Ca}$ at either pH 6 or 9 . Samples with $\mathrm{Ca}$ at $\mathrm{pH} 9$ were observed to have increased peak area and a broader peak compared to those without $\mathrm{Ca}$, which indicates increased association of 2-line ferrihydrite with $\mathrm{COO}^{-}$functional moieties

the increased sorption of $\mathrm{OC}$ at $\mathrm{pH} \geq 7$ with increasing $\mathrm{Ca}$ concentration (Fig. 2), OC-bearing ferrihydrite reacted at $\mathrm{pH} 9$ was analyzed and compared to samples reacted at $\mathrm{pH}$ 6. Past work performing FTIR analysis on $\mathrm{C}$ sorption to Fe oxides has shown major effects of sorption on asymmetric and symmetric $\mathrm{COO}^{-}$(Table 2), which was also observed in our system. The asymmetric $\mathrm{COO}^{-}$band (Fig. 5a) for all sorption complexes shifted from $1585 \mathrm{~cm}^{-1}$ (band location for DOM spectra) to approximately $1570 \mathrm{~cm}^{-1}$. Calcium treatment and $\mathrm{pH}$ did not have an observed effect on the asymmetric band across all samples. However, revealing differences were seen in spectra with increased $\mathrm{Ca}$ and $\mathrm{pH}$ at the symmetric $\mathrm{COO}^{-}$band. The DOM spectrum was found to have a symmetric band at $1400 \mathrm{~cm}^{-1}$, which is analogous to other FTIR studies with organic matter [39-41]. A distinct shift from 1400 to $1384 \mathrm{~cm}^{-1}$ (Fig. 5b) was observed for all sorption samples. Strong evidence exists among OC sorption studies that the shift of the symmetric $\mathrm{COO}^{-}$band, in conjunction with a shift of the

Table 2 Observed peak positions for ATR-FTIR spectra. Peak assignments and references supporting assignment are included

\begin{tabular}{lll}
\hline Peak position $\left(\mathbf{c m}^{-\mathbf{1}}\right)$ & Peak assignment & References \\
\hline $1585-1570$ & Asymmetric COO- stretch & Heckman et al. [42]; Lackovic et al. [39] \\
$1530-1520$ & Aromatic C=C stretch & Chen et al. [8, 14]; Gu et al. [41] \\
1400 & Symmetric COO-stretch & Gu et al. [41]; Fu and Quan [40]; Heckman et al [42]; Lackovic et al. [39] \\
1384 & COO-Fe stretch & Chen et al. [8, 14]; Fu and Quan [40]; Lackovic et al. [39] \\
1270 & Stretching of phenolic OH & Gu et al. [41]; Artz et al. [46]; Chen et al. [8, 14] \\
1250 & OH deformation of COOH & Gu et al. [8, 14]; Heckman et al. [42] \\
1120 & Polysaccharides: C-O stretch & Chen et al. [8, 14]; Heckman et al. [42] \\
1080 & Polysaccharides: C-O stretch & Artz et al. [46]; Chen et al. [8, 14]; Heckman et al. [42] \\
1040 & Polysaccharides: C-O stretch & Chorover and Amistadi [27]; Grube et al. [47] \\
\hline
\end{tabular}


asymmetric band, to $1384 \mathrm{~cm}^{-1}$ is an indicator of an $\mathrm{Fe}$ to carboxylate inner sphere ligand exchange mechanism $[14,39,40]$. Unlike the asymmetric band, OC-bearing ferrihydrite samples formed at $\mathrm{pH} 9$ in the presence of 10 or $30 \mathrm{mM} \mathrm{Ca}$ (medium and high, respectively) were found to have broader peaks with increased peak area compared to samples formed at $\mathrm{pH} 6$, regardless of initial $\mathrm{Ca}$ concentration, and $\mathrm{pH} 9$ with no $\mathrm{Ca}$ concentration. The increased, broader band at $1384 \mathrm{~cm}^{-1}$ for samples pH 9 Medium Calcium (10 mM Ca) and pH 9 High Calcium (30 $\mathrm{mM} \mathrm{Ca}$ ) signifies the increased occurrence of Fe-COO bond formation [39, 40, 42]. This spectral evidence suggests that $\mathrm{Ca}$ is promoting increased association of $\mathrm{Fe}$ and carboxylic functional moieties at $\mathrm{pH}$ 9, which may be occurring due to the formation of $\mathrm{Fe}-\mathrm{Ca}$ carboxylate ternary complexes.

Aromatic $\left(1530-1520 \mathrm{~cm}^{-1}\right)$ and phenolic $\left(1270 \mathrm{~cm}^{-1}\right)$ bands present in DOM spectra were severely diminished or not observed for OC-bearing ferrihydrite sample spectra, suggesting that these functional moieties were not significantly involved in the sorption of $\mathrm{OC}$ to ferrihydrite in our study. Bands at 1120,1080 , and $1040 \mathrm{~cm}^{-1}$ indicate the presence of polysaccharides in the DOM spectra. Other than the $1120 \mathrm{~cm}^{-1}$ band, the 1080 and $1040 \mathrm{~cm}^{-1}$ bands were observed in sorption sample spectra, but with dampened peak intensity. The presence of these peaks suggests that polysaccharide association with ferrihydrite is occurring; however, the association is weak given the low peak intensity and the lack of a shift in the band position. Further examination of these features revealed that all $\mathrm{pH}$ nine samples exhibited increased intensity compared to those formed at $\mathrm{pH} 6$. The increased association of polysaccharides with ferrihydrite at $\mathrm{pH}$ 9 most probably is explained by favorable outer-sphere complexation between $\mathrm{OC}$ and ferrihydrite at high $\mathrm{pH}$, due to the presence of $\mathrm{Ca}^{2+}$ (the $\mathrm{pH} 9$ No Calcium sample has a baseline $1 \mathrm{mM}$ Ca concentration from the DOM solution) and the negative surface charge of ferrihydrite (PZC of 7-7.5) at $\mathrm{pH} 9[5,43]$.

Citric acid-bearing ferrihydrite was also analyzed (Fig. 5c). Shifts similar to what were observed for DOMbearing ferrihydrite samples were found at the asymmetric and symmetric $\mathrm{COO}^{-}$bands. The bands had a high peak intensity as well, suggesting strong binding to ferrihydrite. However, no significant differences in spectra features were observed for samples that received $\mathrm{Ca}$, suggesting that the addition of $\mathrm{Ca}$ has little effect on the binding of citric acid to ferrihydrite.

\section{Potential formation of Fe-Ca-DOM ternary complexes}

The previously discussed batch reactor and ATR-FTIR experiments provide evidence for the synergistic effect of $\mathrm{Ca}$ on DOM sequestration to 2-line ferrihydrite. However, the question remains as to what processes are controlling the increase in DOM sorption in the presence of $\mathrm{Ca}$. Antelo et al. through a combination of batch reaction and modeling studies with ferrihydrite, $\mathrm{Ca}$, and arsenate/phosphate, attributed the synergistic effect of $\mathrm{Ca}$ on phosphate sorption to $\mathrm{Fe}-\mathrm{Ca}$-phosphate ternary complex formation [33]. Organic carbon sorption envelope data paired with corresponding aqueous $\mathrm{Ca}$ data (Figs. 2, 3, respectively) were observed to have similar trends that were observed for phosphate in Anetelo et al. Results from both systems show that $\mathrm{Ca}$ addition limits the decrease in $\mathrm{OC}$, or phosphate, sorption with increasing $\mathrm{pH}$. The congruent results of both systems suggest that our system may also facilitate the occurrence of ternary complexes. Also, the formation of Ca-bridging at high $\mathrm{pH}$ has been thought to potentially have an effect on OM sorption to iron oxides due to the decrease in positively charged surface sites, and subsequent increase in negatively charged surface sites at $\mathrm{pH} \geq 7[23,38]$. Significant concentrations of a divalent cation such as $\mathrm{Ca}^{2+}$ in the presence of negatively charged $\mathrm{OM}$ and a negatively charged ferrihydrite surface may facilitate the bridging processes due to electrostatic favorability $[5,30]$. In addition to potential ternary complex formation, it is also possible that $\mathrm{OC}$ coatings onto ferrihydrite are being formed in the presence of $\mathrm{Ca}$. Due to the high concentration of $\mathrm{OC}$ and increased $\mathrm{Ca}$ adsorption in the presence of DOM, moieties of $\mathrm{OC}$ may be bridged by $\mathrm{Ca}$ which in turn could promote the formation of $\mathrm{OC}$ coatings.

In our study, ATR-FTIR spectroscopy spectra support the ternary associations of $\mathrm{Fe}, \mathrm{Ca}$, and $\mathrm{OC}$. Calcium addition at $\mathrm{pH} 9$ increased symmetric $\mathrm{COO}^{-}$peak intensity compared to samples reacted at $\mathrm{pH} 6$ or $\mathrm{pH} 9$ with no $\mathrm{Ca}$ addition, suggesting greater association of carboxylic moieties of the DOM with ferrihydrite samples reacted with $\mathrm{Ca}$ at $\mathrm{pH}$ 9. Also, the shift of the symmetric $\mathrm{COO}^{-}$band to $1384 \mathrm{~cm}^{-1}$ provides evidence that a ligand exchange mechanism is occurring between Fe and $\mathrm{COO}^{-}$. This shift occurs for all samples, but the distortion of the Ca-receiving spectra suggests the increased occurrence of $\mathrm{Fe}-\mathrm{COO}$ bond formation. Outer-sphere complexes are expected as well due to the electrostatics of the system, especially at high $\mathrm{pH}$. Polysaccharide sorption to ferrihydrite may account for a portion of the outer sphere complexes, if it is occurring, due to increased peak area with no shift at 1080 and $1040 \mathrm{~cm}^{-1}$ at $\mathrm{pH} 9$ compared to $\mathrm{pH} 6$. However, further spectral analysis is needed to pair with the evidence found using ATR-FTIR to continue to probe the mechanism(s) controlling the increased sequestration of $\mathrm{OC}$ in the presence of $\mathrm{Ca}$. 


\section{Conclusions}

Our results suggest that $\mathrm{Ca}$ enhances the extent of $\mathrm{OC}$ sorption to 2-line ferrihydrite from $\mathrm{pH} 4-9$, especially at $\mathrm{pH} \geq 7$. Results from all batch experiments provides evidence for the increased sequestration of $\mathrm{OC}$ up to a $\mathrm{Ca}$ concentration of $60 \mathrm{mM} \mathrm{Ca}$ (Fig. 4). This result aligns with our initial hypothesis as we predicted the increased sequestration of $\mathrm{OC}$ with $\mathrm{Ca}$ amendment due to the proposed formation of $\mathrm{Fe}-\mathrm{Ca}-\mathrm{OC}$ ternary complexes. Citric acid sorption to 2-line ferrihydrite was not significantly affected by the presence of Ca. ATR-FTIR spectroscopic analysis provides evidence for the occurrence of ligand exchange of carboxylate functional moieties to the 2-line ferrihydrite surface and also suggests that $\mathrm{Ca}$ may be promoting the increased formation of $\mathrm{Fe}-\mathrm{COO}$ bonds. Outer-sphere complexation is most likely involved as well but is unable to be directly proven from the ATR-FTIR spectra. It is also possible that Fe-OC-Ca may form at acidic $\mathrm{pH}$ due to the observed increased $\mathrm{Ca}$ adsorption at low $\mathrm{pH}$ in the presence of DOM and the expected positive charge of ferrihydrite below the PZC; however, further batch and spectroscopic work would need to be performed to prove the relative contribution of each potential ternary complex.

The proposed synergistic effect of Ca on DOM sequestration to 2-line ferrihydrite has major implications on how $\mathrm{C}$ cycling should be modeled in terrestrial systems. Understanding the role of $\mathrm{Ca}$ in systems containing both DOM and Fe oxides may provide a key component needed to accurately model the $C$ cycle. Specifically, this work may have significant implications on $C$ sequestration in soils. The common use of $\mathrm{Ca}$-containing soil amendments may have a beneficial effect on OC retention in soils with significant concentrations of Fe oxide, which in turn may affect soil fertility. Addition of $\mathrm{Ca}^{2+}$ via lime application has been observed to increase $\mathrm{OM}$ content in field studies and was attributed to the high concentration of polyvalent cations facilitating decrease of the diffuse double layer, ultimately resulting in increased aggregation [44, 45]. Our work may provide a chemical explanation for increased OC sequestration in $\mathrm{Ca}$-amended soil systems in conjunction with the already proposed physical protection via aggregation. This work is potentially applicable to forest soils as well, due to the source of the natural DOM used in this study, and may prove useful when conducting $C$ research in forest environments. Future work to be performed on this project will focus on analyzing ferrihydrite-Ca-DOM samples by conducting desorption experiments to determine the stability of generated complexes and using a variety of advanced X-ray absorption spectroscopic techniques to provide further evidence of the mechanism of DOM sorption in ternary systems.

\section{Additional file}

Additional file 1: Figure S1. XRD data for synthesized 2-line ferrihydrite. The two labeled broad peaks are characteristic of 2-line ferrihydrite and confirmed we were using the correct Fe mineral phase. Table S1. Aqueous carbon concentrations of DOM stock solution. Table S2. Aqueous elemental composition of DOM stock solution.

\begin{abstract}
Abbreviations
C: carbon; OC: organic carbon; DOC: dissolved organic carbon; DOM: dissolved organic matter; Fe: iron; Ca: calcium; ATR-FTIR: attenuated total reflectanceFourier transform infrared spectroscopy; $\mathrm{COO}^{-}$: carboxylate anion of a carboxylic acid; DRIFT: diffuse reflectance infrared Fourier transform spectroscopy; XPS: X-ray photoelectron spectroscopy; XAS: X-ray absorption spectroscopy; STXM: scanning transmission X-ray microscopy; XRD: X-ray diffraction.
\end{abstract}

\section{Authors' contributions}

TDS conducted all discussed experiments, processed all collected data, and was the primary author for all sections of the manuscript. JWS provided intellectual assistance, assisted with planning experiments, and made manuscript revisions. DLS guided the overall goals of the research project, provided research ideas, and made manuscript revisions. All authors read and approved the final manuscript.

\section{Author details}

${ }^{1}$ Department of Plant and Soil Sciences and Delaware Environmental Institute, University of Delaware, 221 Academy Street, ISE Lab, Newark, DE 19711, USA. 2 Biology Department, Multnomah University, 8435 NE Glisan St, Portland, OR 97220, USA.

\section{Acknowledgements}

The authors thank the UD Soil Testing Lab for assistance running total element aqueous samples, the UD Advanced Materials Characterization Lab, especially Roddel Remy, for ATR-FTIR training, the Stroud Water Research Center for providing a site for collecting OM samples, and the UD Environmental Soil Chemistry group for their support.

\section{Competing interests}

The authors declare they have no competing interests.

\section{Availability of data and materials}

The datasets supporting the conclusions of this article are included within the article and its additional file. Further information may be shared by contacting the corresponding author.

\section{Funding}

This publication was made possible by the National Science Foundation EPSCoR Grant No. IIA-1301765, the State of Delaware, the Delaware Environmental Institute, and the Donald L. and Joy G. Sparks Graduate Fellowship.

Ethics approval and consent to participate Not applicable.

\section{Publisher's Note}

Springer Nature remains neutral with regard to jurisdictional claims in published maps and institutional affiliations.

Received: 26 October 2017 Accepted: 28 January 2018

Published online: 03 February 2018

\section{References \\ 1. Amundson R (2001) The carbon budget in soils. Annu Rev Earth Planet Sci 29(1):535-562}


2. Schmidt MW, Torn MS, Abiven S, Dittmar T, Guggenberger G, Janssens IA et al (2011) Persistence of soil organic matter as an ecosystem property. Nature 478(7367):49-56

3. Riley W, Maggi F, Kleber M, Torn M, Tang J, Dwivedi D et al (2014) Long residence times of rapidly decomposable soil organic matter: application of a multi-phase, multi-component, and vertically resolved model (BAMS1) to soil carbon dynamics. Geosci Model Dev 7:1335-1355

4. Davidson EA, Trumbore SE, Amundson R (2000) Biogeochemistry: soil warming and organic carbon content. Nature 408(6814):789-790

5. Sparks DL (2003) Environmental soil chemistry. Academic press, Cambridge

6. von Lützow M, Kögel-Knabner I (2009) Temperature sensitivity of soil organic matter decomposition — what do we know? Biol Fertil Soils 46(1):1-15

7. Hedges J, Oades J (1997) Comparative organic geochemistries of soils and marine sediments. Org Geochem 27(7):319-361

8. Chen C, Dynes JJ, Wang J, Karunakaran C, Sparks DL (2014) Soft X-ray spectromicroscopy study of mineral-organic matter associations in pasture soil clay fractions. Environ Sci Technol 48(12):6678-6686

9. Michel FM, Ehm L, Antao SM, Lee PL, Chupas PJ, Liu G et al (2007) The structure of ferrihydrite, a nanocrystalline material. Science 316(5832):1726-1729

10. Weng LP, Koopal LK, Hiemstra T, Meeussen JC, Van Riemsdijk WH (2005) Interactions of calcium and fulvic acid at the goethite-water interface. Geochim Cosmochim Acta 69(2):325-339

11. Six J, Conant R, Paul EA, Paustian K (2002) Stabilization mechanisms of soil organic matter: implications for C-saturation of soils. Plant Soil 241(2):155-176

12. Baldock JA, Skjemstad J (2000) Role of the soil matrix and minerals in protecting natural organic materials against biological attack. Org Geochem 31(7):697-710

13. Wagai R, Mayer LM (2007) Sorptive stabilization of organic matter in soils by hydrous iron oxides. Geochim Cosmochim Acta 71(1):25-35

14. Chen C, Dynes JJ, Wang J, Sparks DL (2014) Properties of Fe-organic matter associations via coprecipitation versus adsorption. Environ Sci Technol 48(23):13751-13759

15. Gu B, Schmitt J, Chen Z, Liang L, McCarthy JF (1995) Adsorption and desorption of different organic matter fractions on iron oxide. Geochim Cosmochim Acta 59(2):219-229

16. Schneider M, Scheel T, Mikutta R, Van Hees P, Kaiser K, Kalbitz K (2010) Sorptive stabilization of organic matter by amorphous Al hydroxide. Geochim Cosmochim Acta 74(5):1606-1619

17. Kaiser K, Guggenberger G (2000) The role of DOM sorption to mineral surfaces in the preservation of organic matter in soils. Org Geochem 31(7):711-725

18. Tessier A, Fortin D, Belzile N, DeVitre RR, Leppard GG (1996) Metal sorption to diagenetic iron and manganese oxyhydroxides and associated organic matter: narrowing the gap between field and laboratory measurements. Geochim Cosmochim Acta 60(3):387-404

19. Shaker AM, Komy ZR, Heggy SE, El-Sayed ME (2012) Kinetic study for adsorption humic acid on soil minerals. J Phys Chem A 116(45):10889-10896

20. Mikutta R, Mikutta C, Kalbitz K, Scheel T, Kaiser K, Jahn R (2007) Biodegradation of forest floor organic matter bound to minerals via different binding mechanisms. Geochim Cosmochim Acta 71(10):2569-2590

21. Lalonde K, Mucci A, Ouellet A, Gélinas Y (2012) Preservation of organic matter in sediments promoted by iron. Nature 483(7388):198-200

22. Cismasu AC, Michel FM, Tcaciuc AP, Tyliszczak T, Brown GE Jr (2011) Composition and structural aspects of naturally occurring ferrihydrite. CR Geosci 343(2):210-218

23. Cornell RM, Schwertmann U (2003) The iron oxides: structure, properties, reactions, occurrences and uses. Wiley, Hoboken

24. Jambor JL, Dutrizac JE (1998) Occurrence and constitution of natural and synthetic ferrihydrite, a widespread iron oxyhydroxide. Chem Rev 98(7):2549-2586

25. Kalbitz K, Solinger S, Park J-H, Michalzik B, Matzner E (2000) Controls on the dynamics of dissolved organic matter in soils: a review. Soil Sci 165(4):277-304
26. Stuckey JW, Goodwin C, Wang J, Kaplan A, Vidal-Esquivel P, Beebe Jr. TP, Sparks DL. Impacts of hydrous manganese oxide and goethite on the retention and lability of dissolved organic matter. Biogeochemistry (in revision)

27. Chorover J, Amistadi MK (2001) Reaction of forest floor organic matter at goethite, birnessite and smectite surfaces. Geochim Cosmochim Acta 65(1):95-109

28. Duckworth OW, Holmström SJ, Peña J, Sposito G (2009) Biogeochemistry of iron oxidation in a circumneutral freshwater habitat. Chem Geol 260(3):149-158

29. Waychunas G, Rea B, Fuller C, Davis J (1993) Surface chemistry of ferrihydrite: part 1. EXAFS studies of the geometry of coprecipitated and adsorbed arsenate. Geochim Cosmochim Acta 57(10):2251-2269

30. Kleber M, Eusterhues K, Keiluweit M, Mikutta C, Mikutta R, Nico PS (2015) Chapter one-mineral-organic associations: formation, properties, and relevance in soil environments. Adv Agron 130:1-140

31. Feng X, Simpson AJ, Simpson MJ (2005) Chemical and mineralogical controls on humic acid sorption to clay mineral surfaces. Org Geochem 36(11):1553-1566

32. Post WM, Kwon KC (2000) Soil carbon sequestration and land-use change: processes and potential. Glob Change Biol 6(3):317-327

33. Antelo J, Arce F, Fiol S (2015) Arsenate and phosphate adsorption on ferrihydrite nanoparticles. Synergetic interaction with calcium ions. Chem Geol 410:53-62

34. Kloster N, Brigante M, Zanini G, Avena M (2013) Aggregation kinetics of humic acids in the presence of calcium ions. Colloids Surf A 427:76-82

35. Kloster N, Avena M (2015) Interaction of humic acids with soil minerals: adsorption and surface aggregation induced by $\mathrm{Ca}^{2+}$. Environ Chem 12(6):731-738

36. Bolster $\mathrm{CH}$, Hornberger GM (2007) On the use of linearized Langmuir equations. Soil Sci Soc Am J 71(6):1796-1806

37. Lock K, Criel P. De Schamphelaere K, Van Eeckhout H, Janssen C (2007) Influence of calcium, magnesium, sodium, potassium and $\mathrm{pH}$ on copper toxicity to barley (Hordeum vulgare). Ecotoxicol Environ Saf 68(2):299-304

38. Sposito G (2008) The chemistry of soils. Oxford university press, Cambridge

39. Lackovic K, Johnson BB, Angove MJ, Wells JD (2003) Modeling the adsorption of citric acid onto Muloorina illite and related clay minerals. J Coll Interface Sci 267(1):49-59

40. Fu H, Quan X (2006) Complexes of fulvic acid on the surface of hematite, goethite, and akaganeite: FTIR observation. Chemosphere 63(3):403-410

41. Gu B, Schmitt J, Chen Z, Liang L, McCarthy JF (1994) Adsorption and desorption of natural organic matter on iron oxide: mechanisms and models. Environ Sci Technol 28(1):38-46

42. Heckman K, Vazquez-Ortega A, Gao X, Chorover J, Rasmussen C (2011) Changes in water extractable organic matter during incubation of forest floor material in the presence of quartz, goethite and gibbsite surfaces. Geochim Cosmochim Acta 75(15):4295-4309

43. Eusterhues K, Rennert T, Knicker H, Kögel-Knabner I, Totsche KU, Schwertmann U (2010) Fractionation of organic matter due to reaction with ferrihydrite: coprecipitation versus adsorption. Environ Sci Technol 45(2):527-533

44. Bronick CJ, Lal R (2005) Soil structure and management: a review. Geoderma 124(1):3-22

45. Haynes RJ, Naidu R (1998) Influence of lime, fertilizer and manure applications on soil organic matter content and soil physical conditions: a review. Nutr Cycl Agroecosyst 51(2):123-137

46. Artz RR, Chapman SJ, Robertson AJ, Potts JM, Laggoun-Défarge F, Gogo S, Comont L, Disnar JR, Francez AJ (2008) FTIR spectroscopy can be used as a screening tool for organic matter quality in regenerating cutover peatlands. Soil Biol Biochem 40(2):515-527

47. Grube M, Lin JG, Lee PH, Kokorevicha S (2006) Evaluation of sewage sludge-based compost by FT-IR spectroscopy. Geoderma 130(3):324-333 